\title{
Inter-agency Co-operation in Activation: Comparing Experiences in Three Vanguard 'Active' Welfare States
}

\author{
Colin Lindsay and Ronald W. McQuaid \\ Employment Research Institute, Napier University Business School, Craiglockhart 03/50, Edinburgh, UK \\ E-mail: C.Lindsay@napier.ac.uk
}

New forms of inter-agency co-operation have gained increasing prominence in the development and delivery of activation strategies. This article compares different models of inter-agency co-operation, drawing on case study research in Denmark, the Netherlands and the UK. The different models have reported variations in performance when delivering on the key benefits often attributed to effective inter-agency co-operation. The article raises concerns that the process of contracting-out in activation has at times conflicted with attempts to improve co-operation between agencies, while the increasing dominance of purchaser-provider relations can undermine progress towards 'shared ownership' of activation policies and effective partnership-working.

\section{Introduction and methodology}

Inter-agency co-operation and activation

New forms of inter-agency co-operation have gained increasing prominence in the development and delivery of activation strategies. Successive formulations of the European Employment Strategy have called for local partnership-working as a means of ensuring responsive activation services, while arguing for the 'progressive de-monopolisation' of interventions once dominated by Public Employment Services (PES) (Lindsay, 2007). More generally, the concept of inter-agency co-operation, and specifically partnership, in service delivery emerged during the 1980s and 1990s as a canon of public policy and private enterprise (Knox, 2002). While there are a multitude of definitions of partnership, the OECD (1990: 18) has suggested that the term can be deployed to cover a broad range of: 'Systems of formalised co-operation, grounded in legally binding arrangements or informal understandings, co-operative working relationships, and mutually adopted plans among a number of institutions.'

Such broad-based definitions tend to assume that the concept of partnership can usefully encapsulate both systemic co-ordination (embedded multi-agency governance based on a shared vision and institutionalised joint-working) and principal-agent relations, which may include competitive tendering models favoured under the contracting-out of public services (Stoker, 1998). Some dispute the inclusion of principal-agent contracting as a form of partnership, arguing that trust is a key feature of the kind of 'networked governance' that defines genuine partnership-working, and that contracting refers to a different form of relationship (Powell and Exworthy, 2002). But it has also been noted that, rather than simply seeking to impose private sector inputs, policy makers drawn towards contracting-out often seek similar benefits to those attributed to partnership-based forms of inter-agency co-operation. There is an acknowledgment among these policy makers of 
the multi-dimensional nature of the disadvantage experienced by excluded groups, and that multi-agency solutions are required to assist them (Stoker, 1998; McQuaid, 2000).

Nevertheless, a fundamental issue relates to the extent to which contracting-out can be seen as a necessary feature of effective partnerships, or as even compatible with such collaborative forms of inter-agency co-operation. There is evidence that partnership-working and contracting-out are not always mutually exclusive (Rummery, 2002), but a key question for our research focused on the compatibility of planning and implementation partnerships (characterised by the sharing of resources and decisionmaking) with contractual models of delivery defined in terms of 'payment by results'. As we note below, while partnership-working and contracting-out have co-existed in our case study countries, policy makers have often struggled to reconcile these different approaches to promoting inter-agency co-operation.

\section{Mapping potential benefits and limitations of inter-agency co-operation}

This article discusses different models of inter-agency co-operation in the governance and delivery of activation, focusing on three leading 'active' welfare states: Denmark, the Netherlands and the UK. We seek to identify common and divergent trends in the localisation and contracting-out of services; explore how effectively different models have been able to tap the key benefits attributed to effective inter-agency co-operation; and identify the limits on co-operation that are inherent within different governance and delivery arrangements.

There is a substantial literature on the potential 'partnership benefits' associated with effective inter-agency co-operation in all its forms. For the purposes of the discussion below, we focus on six key benefits of effective partnerships consistently raised in the literature (see McQuaid, 2000; Nelson and Zadek, 2000; Dowling et al., 2004; McQuaid et al., 2005 for a review of research).

- Local flexibility and responsiveness. Given the complexity of the issue of social and labour market exclusion, and its sensitivity to local economic conditions, it is suggested that multi-agency approaches grounded in local labour markets are necessary to facilitate the tailoring of interventions to specific local circumstances.

- Sharing knowledge, expertise and resources. Bringing together a range of stakeholders with different areas of expertise can offer opportunities to share practice and information, while the 'local knowledge' of community-level stakeholders can be invaluable in developing solutions targeted at the specific needs of disadvantaged areas or groups. Partnerships can also add to the total level of resources available by increasing the number of budget-holding organisations involved.

- Improving efficiency. Advocates of partnership-based approaches suggest that the synergies available from close co-operation (whereby information sharing and improved communication results in smoother service interactions and the avoidance of duplication of effort) improves overall efficiency.

- Developing joined-up services. During the policy planning phase, strategic level partnerships can ensure that initiatives across areas of government activity are aligned to achieve a coherent, integrated and long-term approach. Closer collaboration between agencies often aims at providing a consistent level of service and a convenient, 'one stop' environment for service users. 
- Capacity building. Multi-agency partnerships can build community capacity and engender a sense of 'shared ownership' at the local level. In countries such as the UK, the voluntary sector and local community organisations have increasingly found themselves called upon to assist in the delivery of government-funded activation. For these stakeholders, co-operation with government offers new opportunities to have a practical impact on the policy agenda, while also providing access to long-term, stable funding.

- Gaining legitimisation and 'buy-in'. Governments have long been aware that engagement of non-governmental stakeholders can provide legitimisation, and the mobilisation of political support, for new policy goals. During the delivery phase of initiatives, the engagement of community-level stakeholders can similarly add to the credibility of interventions. As we will see below, where governments have demonstrated a willingness to share a degree of decision-making authority with other agencies, these stakeholders are more likely to 'buy-in' to the process, and commit themselves to making interventions work.

The extent to which different models of inter-agency co-operation on activation have been able to deliver these benefits provides the focus for the discussion below. However, it is worth noting at this early stage the inherent limits to co-operation. Where attempts have been made to build locally responsive, multi-agency solutions, effective inter-agency co-operation can be undermined by the rigidity of institutional and policy structures; where partnerships are advocated as a means of building capacity in the voluntary sector, community organisations can find their independence undermined. Finally, where multiagency solutions are based on contracting-out, the benefits associated with the purchase of more specialist provision can be undermined by problems associated with transaction costs and the subordination of quality to financial concerns.

\section{Methodology}

Our discussion draws on case study research conducted in the three countries. In each case, the research involved case study visits to organisations involved in the governance and delivery of activation at the local and regional and/or national levels. Specifically, stakeholders in each country consulted for the research were as follows:

- Denmark: the government's national Labour Market Authority; national and regional Trades Union Congress representatives; national and regional representatives of the main employers' federation ('Dansk Arbejdsgiverforening'); PES managers based in the 'Greater Copenhagen' region; and a community-level activation provider delivering provision for job seekers in inner-city Copenhagen (7 in-depth interviews).

- The Netherlands: the government Ministry of Social Affairs and Employment; national and regional PES managers; national and regional managers at the Administrative Agency for Employees' Insurance (UWV); the national representative body for local authority social services department managers (DIVOSA); a local authority manager in the city of Rotterdam; and a major, Rotterdam-based private sector activation provider (9 in-depth interviews). 
- The UK: regional PES managers; policy officers within the devolved governments of Scotland and Northern Ireland; health service managers and staff involved in the 'Pathways to Work' programme in two regions; community-level activation providers delivering provision for job seekers in the cities of Edinburgh and Belfast; and a major private sector activation provider based in the city of Birmingham (15 in-depth interviews).

In each country, interviewees were selected in order to gain insights into the most important and/or most innovative forms of inter-agency working within the activation policy agenda. Accordingly, government, PES and social partner representatives with an insight into the reform of Denmark's distinctive regional partnership structures were targeted. In the Netherlands, recent jobcentre developments have required co-operation across the PES, the unemployment insurance administration and local authorities, and private sector contractors - representatives of these stakeholders were therefore interviewed. In the UK, interviews were carried out with PES officers who oversee contracting-out and private, public and community sector providers involved in delivering PES-funded provision under both contractual arrangements and partnership-based pilot models.

\section{Denmark: from regional partnerships to joined-up local services}

Inter-agency co-operation in Denmark

Denmark has been consistently highlighted as a key 'active' welfare state in Europe, with successive governments overseeing a series of reforms to convert the country's once largely passive welfare state into a leading exponent of activation strategies. Despite its relatively recent emergence, with many elements of the current system introduced since 1994, the Danish approach to activation has reflected a combination of long-standing policy traditions: a strong, centralised state-led approach to the development of policy, typical of many 'social democratic' welfare states in Nordic Europe; and an active role for social partnership and, more recently, local government in the planning and implementation of policy.

From 1994 to 2006, Regional Labour Market Councils (RARs), with membership from social partner (employer and trade union) organisations and local authorities played an important role in agreeing activation targets and programme content for the insured unemployed in 14 PES regions. ${ }^{1}$ The 2007 re-organisation of local and regional government in Denmark saw major changes to the governance of activation. Four new 'state-region'-level Employment Councils replaced RARs. PES and local authorityled service centres were amalgamated within 91 one-stop-shop jobcentres. However, the decision-making authority and influence enjoyed by RARs have been lost. The targeting and resourcing of activation are now the remit of PES and local authorities alone, based on agreements reached with the government Labour Market Authority (LMA). Finally, the period since 1994 has seen a gradual increase in the importance of contractual relationships with external service providers. By 2005, there were 159 recognised activation providers nationally, two-thirds of which were private companies, with the remainder trade union or unemployment insurance fund organisations and further education institutions. 
One of the main advantages associated with the regional structures that operated in Denmark from 1994 to 2006 appears to have been that - within clear, centrally defined parameters - key stakeholders were able to discuss and agree targeted local responses. RARs operating at the city-regional level delivered a degree of the local flexibility and responsiveness that marks successful planning partnerships. A government LMA representative noted the importance of 'giving concrete decision-making authority to the regions' (in relation to the content and target groups for some interventions) in order to develop flexible solutions. Greater Copenhagen RAR members gave a number of examples of this flexibility in action, including the targeting of resources towards the needs of minority ethnic and immigrant job seekers (a much larger client group in Copenhagen than in any other part of Denmark).

Regional and national stakeholders were divided as to whether the process of localisation implemented from 2007 would improve the responsiveness of services. PES and municipality officials shared the view that a more locally responsive set of policy initiatives could emerge. However, some trade union and employer representatives were concerned about the limited capacity within smaller local authorities. There was also scepticism regarding the impact of contracting-out. The use of a broader range of external providers has been justified as providing a route to more responsive, flexible interventions, but trade union representatives and even some PES managers noted that progress in this area had been variable and limited.

Stakeholders noted the value of RAR structures in sharing knowledge, expertise and resources, bringing together the PES, employers' representatives, trade unions and local authorities. There was concern that the shift towards a localised jobcentre model threatened progress in this area. Accordingly, PES and trades union and employers' representatives highlighted the importance of 'securing knowledge' during the process of reform. This was considered important given the shift towards local authority-level provision and the resulting dispersal of some PES officers (and their expertise) from regional to local centres.

Evidence on the impact of former regional and new local governance structures in improving efficiency was less clear. PES managers and employers' representatives argued that RAR processes had often been time-consuming (although there was a sense among even these stakeholders that the bureaucracy associated with RARs was justified by the sense of shared accountability and 'ownership' that emerged from joint decisionmaking). Government LMA representatives argued that contracting-out had the potential to deliver increased efficiency, a view shared by some employers' representatives, but other stakeholders were unconvinced. Trade union representatives suggested that a focus on the mechanics of marketisation had often obscured the lack of clear evidence (as yet) of improved services.

There was optimism regarding the potential impact of new localised jobcentres in delivering a more efficient 'one string' system for job seekers, and in general the reform was seen as offering the opportunity for developing joined-up services. The shift towards a jobcentre model that would allow learning and practice-sharing between PES and local authorities was also seen by all stakeholders as a means of promoting local capacity building.

Perhaps the most consistently raised concern regarding the process of localisation referred to the manner in which RARs had been effective at gaining legitimisation and 
'buy-in', and the danger that progress in this area would be undermined by the abolition of regional planning structures. A number of stakeholders noted the value of RAR structures in gaining the support of key interest groups, such as trade unions and employers. For a government LMA representative, the legitimacy provided by the active involvement of a key employers' association had made it easier to engage business (crucial to the successful operation of wage subsidy programmes). Similarly, it was suggested that the role of trade unions in regional planning had helped to legitimise compulsory programmes in the eyes of the unemployed.

Crucially, it was acknowledged that the genuine (if limited) shared authority and decision-making power within the RAR model had promoted a sense of ownership among partner organisations. By ceding and sharing some responsibility for the planning, funding and targeting of activation with employers and trades union organisations (as well as local authorities), the then Danish government ensured that these organisations had a stake in, and sense of responsibility for, seeing that programmes worked. The local and regional advisory councils that have replaced RARs deny social partners a proactive role in the planning and development of activation, potentially undermining the sense of commitment among employers and trade unionists.

\title{
The Netherlands: hollowing out the PES, contracting-out activation
}

\author{
Inter-agency co-operation in The Netherlands
}

The Netherlands' labour market policy institutions have experienced a process of rapid and almost constant reform since the 1980s. Tripartite institutions that gave social partners an important role in the administration of insurance-based benefits, and latterly the management of the PES, were introduced and then dissolved. A process of marketisation starting in the 1990s saw insurance fund organisations and local authorities (dealing with unemployment insurance and income-based benefit claimants respectively) required to purchase activation services in a new market, which was initially dominated by the PES (Borghi and Van Berkel, 2007).

More recently, the 2002 'SUWI' Act (meaning 'implementation structure for work and income') established the UWV - functioning under the control of the Ministry of Social Affairs and Employment - as the single management body for benefits and activation for the insured unemployed. Local authorities remained in charge of social assistance benefits and services. Successive reforms to funding mechanisms have granted each municipality a greater degree of autonomy over the delivery of activation, but also total financial and budgetary responsibility.

A series of reforms has also resulted in the privatisation of those areas of PES activity involving the delivery of intensive activation. The role of the PES (known as Centre for Work and Income - CWI) is now largely limited to 'gate-keeping' - assessing clients and providing job matching services for the least disadvantaged. The UWV and local authorities are the main funders/purchasers of activation services, while the government has insisted that $70 \%$ services purchased by the UWV (and, until recently, the majority of those purchased by local authorities) are delivered by private sector organisations. At the same time, integrated local jobcentres (CWI's) have been established, co-locating staff from the PES, and the two types of funder/purchaser organisations. 
Key stakeholders interviewed for our research were committed to the Centres for Work and Income approach, and strongly advocated the continued co-location and integration of services as a route to increased local flexibility and responsiveness in services. National government officials pointed to the benefits for clients in being able to access both benefits advice and job search services from expert organisations at the same location.

Ministers have expressed the hope that the outsourcing of activation will also contribute to the development of more individually tailored, locally responsive services. But government officials and local stakeholders acknowledged that progress towards more responsive, flexible provision has been slow. Indeed, representatives of both local authorities and the UWV accepted that the pressure of competing on cost had driven many private sector providers to seek economies of scale through standardised approaches. It should, however, be acknowledged that both key funders - the UWV and local authorities - remained optimistic that a more flexible approach would soon emerge with the rollout of 'Individual Reintegration Accounts' and 'Personal Reintegration Budgets'. These funding arrangements have been used to provide a modular, voucher-type system designed to allow the activation client a wider range of choice in activation.

All local and regional stakeholders also valued the Centres for Work and Income model as a means of sharing knowledge, expertise and resources. It was suggested that the co-location of different organisations in Centres for Work and Income has helped to foster improved joint-working and communication, and a better understanding of each agency's procedures and roles. Nevertheless, PES managers acknowledged that they were not 'equal partners' in deciding clients' trajectories, and activation funders were even less convinced of their influence.

In more general terms, the contractual relations that are at the heart of the management of activation in the Netherlands may also act as a barrier to genuine partnership working. Private sector providers have a key role in delivering services on the ground and can therefore offer valuable insights as to 'what works', but the unequal power that defines contracting may inherently limit their ability to influence funders. A UWV manager dismissed the idea that contracted providers could be seen as partners in assessing the best activation trajectory for clients: 'There is certainly no partnership. It's a contractual relationship. We have discussions, and companies make presentations about what they can offer.'

The Centres for Work and Income approach was viewed as contributing to improving efficiency. Improved communication and information sharing was seen as reducing errors, misunderstandings and paperwork at the operational level. Most regional and national stakeholders agreed that it was 'too early to tell' if contracting-out had produced the desired efficiencies. All the relevant stakeholders acknowledged some problems around transaction costs and new bureaucracy. Despite these problems, national and local government interviewees shared the view that setting clear budgets and targets for private providers had the potential to improve performance. A local authority representative argued that contracting-out had resulted in a stronger sense of control, contrasting current arrangements with some previous municipality-delivered activation programmes that were 'governed by their own logic', 'reversed normal economic principles and ... operated for their own sake'.

There was agreement that the greatest value of Centres for Work and Income was their contribution to developing joined-up services and presenting unemployed clients 
with a 'one stop shop'. National and regional stakeholders similarly highlighted the value delivered by Centres for Work and Income in relation to capacity building. UWV and local authorities' representatives saw the Centres as offering an opportunity for PES staff to learn about benefits regulation and activation options. However, for one regional PES manager, additional measures to build professional capacity among local authorities remained necessary. It was suggested that the switch to a market-based approach in which virtually all activation services have been contracted-out has left local authorities with few professionals with direct experience of dealing with clients' problems (and limited experience in purchasing and managing privatised services).

This highlights a broader concern with the Dutch model. Much of the expertise formerly held by the PES has now been transferred to the private sector (with PES professionals largely limited to registering clients and facilitating job search for the most able), while key public purchasers have limited direct contact with clients. Accordingly, there is a danger that the public sector will suffer a loss of crucial 'intellectual capital' the institutionalised knowledge of 'what's needed' and 'what works' that only comes from direct engagement with clients and service providers on the ground. The marginalisation of the role of the PES may also have implications for the consistency of services, in turn impacting on the ability of delivery agencies in different localities to gain legitimisation and 'buy-in' for activation.

\section{The UK: 'Centralised localism' and the retreat from partnership}

Inter-agency co-operation in the UK

The Labour government elected in the UK in 1997 has consistently deployed the language of partnership in relation to its reform of the governance and delivery of activation (Lindsay, 2007). The New Deal - the UK's main group of compulsory activation programmes established between 1997 and 2000 - was initially designed and implemented at the local level through 'New Deal Partnerships', led by the PES, but including a range of public, private and voluntary sector actors. However, local experimentation soon gave way to a standardised approach, with the PES assuming the sole lead role in most areas. New Deal Partnerships have now disappeared. The standard UK approach to activation instead involves a strong role for the PES in directly delivering job matching and basic counselling ('Personal Adviser') services under programmes such as New Deal, and managing contracts with external providers who carry out more specialist interventions. ${ }^{2}$ Although models of contracting are fairly rigid, a range of public, private and voluntary sector providers are involved in delivery.

With the expansion of the UK's activation agenda a familiar pattern has emerged, where flexible funding arrangements and partnership-based governance are relied upon to test new, experimental interventions during their 'pilot' phase, but centralised contractualism (often governed by rigid, job outcome-driven reward systems) are imposed when programmes are rolled out nationally. For example, 'Employment Zones', operating in areas of high unemployment since 1998, initially sought to experiment with flexible funding mechanisms, with resources allocated following consultation between the PES (the funder) and other local stakeholders. The roll-out of the programme nationally has seen a more standardised form of contracting-out between the PES and private 'lead partners', which then often sub-contract aspects of delivery to other agencies (Bruttel, 2005). 
Similarly, the piloting of 'Pathways to Work' (which seeks to activate those claiming health-related incapacity benefits, and which provided a particular focus for our research) has involved a highly flexible funding model, with the PES sharing responsibility for the development and management of a 'Condition Management Programme' with public National Health Service (NHS) managers. Flexible funding structures allowed NHS managers considerable freedom in recruitment of staff and resourcing of programme development (Lindsay et al., 2007). However, government promises that in 'future Pathways to Work provision will be delivered primarily by the private and voluntary sectors, with payment by results' (HM Treasury, 2006: 43) suggest that the partnershipbased approach that defined the pilot phase of the programme is again in danger. In general terms, the UK model has been characterised as a form of 'centralised localism' (Lødemel, 2001), with the PES largely controlling the design and content of programmes, and local 'partners' tendering to provide pre-agreed services within a set contracting structure, rather than contributing to the planning of flexible solutions on equal terms.

\section{Benefits and limitations of inter-agency co-operation}

Despite long-standing concerns regarding the UK model's reliance on centralised contractualism, regional PES managers and other key stakeholders argued that there remained the capacity for a range of providers to be contracted to deliver tailored services, ensuring some local flexibility and responsiveness. It was suggested that the 'opening up' of the delivery of activation to include the private and voluntary sectors (produced by the first wave of New Deal reforms) has generally had a positive impact on the diversity of provision available, while contributing to capacity building, especially among voluntary organisations. Where pilot programmes have allowed for more flexible relationships between the PES and other stakeholders, such as under Pathways to Work, there have been further opportunities for capacity building - in this case PES advisers and NHS health professionals were able to work with clients together, learning from each other's experience and expertise.

All PES managers agreed that the inclusion of a broader range of providers had facilitated the sharing of knowledge and expertise, although it was acknowledged that resource-sharing under programmes such as New Deal was subject to contractual arrangements clearly articulating the outcomes required by the PES as funder. Among other stakeholders (for example, local authority managers involved in the development of complementary activation initiatives) there was frustration that the PES's role as purchaser of services precluded a fuller engagement and information-sharing with local public and voluntary sector providers.

PES managers were convinced that clearly defined contractual arrangements were essential to improving efficiency (although there was an openness to contracting with public and voluntary organisations, as well as the private sector). Other stakeholders were less convinced that contracting-out had delivered improved efficiency. Indeed, in the case of Pathways to Work, there appeared to be substantial efficiencies associated with the more flexible form of partnership-working established during the programme's pilot phase. The engagement of the NHS as a partner allowed for economies of scale provided by access to the organisation's networks of expertise, facilities and support services.

Finally, the inclusion of a broad range of contracted providers has arguably added value in delivering a degree of legitimisation and 'buy in'. As noted above, a strength of 
the UK model of contracting is its openness to working with providers in the public sector (including local authorities) and specialist voluntary and community-based organisations. PES managers and other key stakeholders acknowledged that the inclusion of expert delivery agencies (especially those with an established reputation for working in local communities) added to the perceived legitimacy of activation among job seekers. The recently developed Pathways to Work again offers valuable lessons. Previous attempts to activate claimants of incapacity benefits have generated hostility among many, but both PES and NHS staff involved in Pathways to Work suggested that the participation of health professionals had reassured clients that the programme was a credible service with the capacity to improve their health (as well as their employability).

However, a recent shift towards private sector-led, contracted-out approaches under Pathways to Work could put at risk partnership-based governance developed during the programme's pilot phase. Pathways to Work appears to be about to fall victim to a familiar process in UK employability policy making, whereby innovative strategies are developed under flexible funding and partnership-based governance during piloting, only for policy makers to sanction a retreat from partnership towards more rigid forms of managerialism and contractualism as programmes are rolled out nationally.

\section{Discussion and conclusions}

EU member states are increasingly turning to inter-agency co-operation as a means of planning and implementing activation. The results of the case study research discussed above confirm a shared focus on local collaboration and the inclusion of a diverse range of delivery agents. Both Denmark and the Netherlands have moved towards a localised, integrated jobcentre model bringing together PES and local authorities' services. In the UK, local authorities tend to offer their own complementary employability services, but are not integrated within jobcentres (reflecting the manner in which local government is not responsible for administering social assistance in the UK), while the PES dominates jobcentre services and activation programme development and contracting.

Locating new forms of inter-agency governance and delivery at an appropriate spatial level has been a priority for policy makers in all the case study countries, with processes of localisation often (but not always) seen as complementing and facilitating co-operation. In all cases there are important potential benefits associated with the co-location and closer integration of services - 'one stop' jobcentres provide more joined-up services (including the welcome integration of provision for claimants of different benefits) and should promote capacity building and the sharing of knowledge and expertise between agencies. However, we have noted how differential power relationships have the potential to undermine partnership-working (especially in cases such as the Netherlands, where the PES's lack of budget control limits its ability to influence activation trajectories). The Danish experience also highlights how the shift towards localisation has the potential to undermine effective existing partnership-working, which, in the case of RARs, saw the PES share ownership of activation planning with social partners, ceding a degree of decisionmaking authority to these stakeholders and thus ensuring a greater degree of legitimisation and 'buy in' for interventions. There also remain questions about the capacity of local authority-level stakeholders to manage activation and effectively co-ordinate activities within and across regions. 
Furthermore, the experience of localisation and service integration in Denmark and the Netherlands raises concerns about the capacity to ensure a consistent level of basic services following the weakening of the role of the PES. In the Netherlands, the establishment of Centres for Work and Income and the contracting-out of previously PES-led activation has left the organisation (like the local authorities and UWV that fund services) with limited direct contact with more disadvantaged clients, resulting in a potential loss of intellectual capital - the kind of institutionalised knowledge that only comes from direct engagement in the delivery of services. In Denmark, the dismantling of regional PES structures risks dispersing the expertise held within the organisation too thinly.

All three case study states have seen a more general trend towards the contractingout of activation. The stated aim is to increase the range of specialist, individualised support available to clients, and improve the efficiency and responsiveness of delivery. Yet in all cases there remain questions about the capacity of contractualism to deliver the innovation and responsiveness sought from multi-agency approaches - the unequal power between purchaser and provider limits the potential for sharing ideas; the shortterm nature of some contracts (as in the Netherlands) can undermine attempts to build consistent, long-term interventions; the rigidity of certain forms of contracting (as in the UK) can actively discourage partnership-working; and the process of marketisation in itself can prevent specialisation, as providers seek efficiencies in the battle for limited funding.

As noted above, in the case of the Netherlands, the large-scale contracting-out of PES activities has also contributed to the hollowing out of this key public organisation, threatening the consistency of services and leaving policy makers with limited sense of connection to the practical issues around delivering services for job seekers on the ground. The UK government's interest in promoting private sector leadership in the delivery of activation suggests that a similar process of hollowing out may be repeated here - a recent government-supported review has argued for the large-scale contracting-out of provision to private providers (Freud, 2007). Indeed, as the Pathways to Work programme highlighted above has been rolled out nationally, there has already been a decisive shift towards contracting-out, with private sector 'lead providers' now managing the majority of provision (DWP, 2007). There is some evidence that this change has already limited the ability of the PES to build upon pre-existing partnerships with NHS health organisations. PES 'Personal Advisers' (who previously played a key role in delivering tailored services for Pathways to Work clients) have also seen their advice work contracted-out in some areas. Like PES officers in the Netherlands, these professionals have been limited to a registration and job matching role - a shift that similarly threatens to undermine the capacity of government to directly deliver (and therefore ensure the consistency and quality of) more intensive support services.

Comparing trends across the three countries, it is clear that the Netherlands has gone furthest towards a contractual model, but that the UK's already extensive contracting-out of specialist provision may soon lead to a similar outsourcing of PES-led intensive activation and employment services. Denmark's experiment with contracting-out has been more gradual and halting, reflecting the lack of political consensus (and perhaps the weakness of private sector capacity) in a country that has strong traditions of social partnership in planning and public sector leadership in the delivery of services.

Genuine partnership-working requires the ceding of authority and sharing of resources and responsibilities. Where implemented, such partnerships can deliver rewards 
in terms of enhanced knowledge sharing, improved efficiency and greater legitimacy for activation through a sense of shared ownership (and therefore commitment to making interventions work) among key stakeholders. Such shared ownership has proved difficult to establish and maintain in all three of these vanguard active welfare states. Specifically, it remains unclear if an increasing reliance on the contracting-out of PES functions (especially in the UK and the Netherlands), and the unequal distribution of power and resources implied by such arrangements, can be fully reconciled with partnershipworking. Yet effective inter-agency co-operation in the governance and delivery of activation remains most likely within partnerships where strong PES organisations retain a key role in the management and (if appropriate) delivery of services, but are also empowered to share resources and decision-making authority with other stakeholders.

\section{Notes}

1 From 1998, Local Co-ordination Committees advised municipalities' development of policies for social assistance claimants, but lacked the power of RARs to influence the use of budgets and target services on specific client groups.

2 The administration of both insurance-based and social assistance benefits has been the responsibility of a single PES organisation, Jobcentre Plus, since 2002. Services for claimants of insurancebased and social assistance benefits are fully integrated in the UK. Local authorities play no role in the delivery of basic benefits and services for job seekers, but can deliver activation programmes (in some cases as a PES-contracted provider).

\section{References}

Borghi, V. and Van Berkel, R. (2007), 'New methods of governance in Italy and the Netherlands: the case of activation policies', Public Administration, 85, 1, 83-101.

Bruttel, O. (2005), 'Are employment zones successful? Evidence from the first four years', Local Economy, 20, 4, 389-403.

Dowling, B., Powell, M. and Glendinning, C. (2004), 'Conceptualising successful partnerships', Health and Social Care in the Community, 12, 4, 309-17.

DWP (Department for Work and Pensions) (2007), Speech by Rt Hon Peter Hain MP, Secretary of State for Work and Pensions, at the Institute for Public Policy Research, 12 September, London, DWP.

Freud, D. (2007), Reducing Dependency, Increasing Opportunity: Options for the Future of Welfare to Work, London: DWP.

HM Treasury (2006), Lisbon Strategy for Jobs and Growth: UK National Reform Programme -Update on Progress, London: HM Treasury.

Knox, C. (2002), Review of Public Administration: Partnerships, Belfast: Office of the First Minister and Deputy First Minister.

Lindsay, C. (2007), 'The United Kingdom's "Work First" welfare state and activation regimes in Europe', in A. Serrano Pascual and L. Magnusson (eds), Reshaping Welfare States and Activation Regimes in Europe, Brussels: Peter Lang, pp. 35-71.

Lindsay, C., McQuaid, R.W. and Dutton, M. (2007), 'New approaches to employability in the UK: combining "human capital development" and "Work First" strategies?', Journal of Social Policy, $36,4,539-60$.

Lødemel, I. (2001), 'Discussion: workfare in the welfare state', in I. Lødemel and H. Trickey (eds), An Offer You Can't Refuse: Workfare in International Perspective, Bristol: Policy Press, pp. 295-345.

McQuaid, R.W. (2000), 'The theory of partnerships - why have partnerships?', in S.P. Osborne (ed.), Managing Public-Private Partnerships for Public Services: An International Perspective, London: Routledge. 
McQuaid, R.W., Lindsay, C. and Greig, M. (2005), 'Job guarantees, employability training and partnerships in the retail sector', Local Economy, 20, 1, 67-78.

Nelson, J. and Zadek, S. (2000), Partnership Alchemy: New Social Partnerships in Europe, Copenhagen: Copenhagen Centre.

OECD (Organisation for Economic Co-operation and Development) (1990), Partnerships for Rural Development, Paris: OECD.

Powell, M. and Exworthy, M. (2002), 'Partnerships, quasi-networks and social policy', in C. Glendinning, M. Powell and K. Rummery (eds), Partnerships, New Labour and the Governance of Welfare, Bristol: Policy Press.

Rummery, K. (2002), 'Towards a theory of welfare partnerships', in C. Glendinning, M. Powell and K. Rummery (eds), Partnerships, New Labour and the Governance of Welfare, Bristol: Policy Press.

Stoker, G. (1998), 'Public-private partnerships and urban governance', in J. Pierre (ed.), Partnerships in Urban Governance: European and American Experience, Basingstoke: Macmillan. 